\title{
Contrato social y posapocalipsis en Los perros del fin del mundo y Ciudad de zombis de Homero Aridjis
}

\author{
Aurelio Iván Guerra FÉLIX*
}

\section{Resumen:}

El mundo posapocalíptico en la ficción suele representarse como un sitio hobbesiano en el que la ausencia de un contrato social mantiene al hombre en una lucha constante por la sobrevivencia. En Ciudad de Zombis y Los perros del fin del mundo, Homero Aridjis representa el México actual como un sitio distópico sin más orden ni ley que la que impone el crimen y la violencia. A pesar de este escenario, el espacio representado en estas novelas no carece de contrato social, pues en este se mantienen activas las instituciones de la vida moderna. En este artículo propongo que esta situación contradictoria apunta a una interpretación posapocalíptica de la sociedad en el México contemporáneo.

Palabras clave:

Postapocalipsis, Homero Aridjis, contrato social, novela mexicana contemporánea.

De entre los imaginarios por los que puede discurrir la ficción posapocalíptica, quizá el más común sea el de representar el colapso del "contrato social" luego de la catástrofe. Es tan recurrente este escenario en la literatura contemporánea que ha venido a definir

* Universidad de Sonora. 
los parámetros actuales del género mismo. Hoy difícilmente puede imaginarse una realidad posapocalíptica en ningún otro sentido; ha quedado clausurado, más que cualquier otra opción, aquel futuro utópico milenario prometido en el mismo Apocalipsis de San Juan.

No todo el posapocalipsis del imaginario contemporáneo es destrucción y muerte: en el mundo después del fin el lector podrá encontrar la infraestructura urbana intacta, incluso al mismo planeta rebosando de vida, pero no hallará en esta ficción, salvo en casos excepcionales, más que rastros de las instituciones sociales que eran necesarias para la existencia humana a gran escala: estas habrán sucumbido a la fuerza brutal del "hombre natural" hobbesiano. Es por eso que la ficción posapocalíptica contemporánea se entiende mejor en términos de una discusión del contrato social que meramente como ansiedades relacionadas con la supervivencia luego del fin de las comodidades modernas.

$\mathrm{Al}$ presentarnos este tipo de situaciones que van más allá de los límites -en este caso el límite que debe imponer el fin del mundola ficción invita a los lectores a reflexionar sobre las virtudes y defectos de las instituciones sociales presentes y las comodidades o vicios que se desprenden de ellas. De ahí el didactismo de este género narrativo, pues apunta hacia lo que se debe valorar como sociedad y como individuos para sobrevivir, no al apocalipsis, sino al "día después" del apocalipsis (Curtis 17). Así que, a pesar de los excesos de destrucción y tragedia en los que esta ficción se suele regodear, y a pesar de narrar acciones y eventos que son ajenos a la sensibilidad Ilustrada, la ficción posapocalíptica, en su optimismo, es uno de los pocos géneros literarios contemporáneos que mantienen vigente el programa del Siglo de las Luces, en tanto que busca reformar la sociedad contemporánea mediante propuestas centradas en la razón sobre lo que debe contener el contrato social.

En algunos casos la ficción posapocalíptica alaba la capacidad de quienes logran empezar una nueva sociedad a partir de cero con un contrato social actualizado, si bien limitado y básico, como sucede, por ejemplo, en Malevil de Robert Merle o en Los genocidas de Thomas Disch. El nuevo contrato social se nos presenta como una institución depurada de los excesos superfluos que mantienen 
encumbrado a un reducido grupo de individuos carentes de aptitudes naturales de supervivencia. En otros casos la ficción posapocalíptica nos ofrece un retrato del otro extremo: el del hábitat y la figura del 'hombre natural' embrutecido y hasta despojado de sentido biológico, ya sea en su papel de zombi o bien, entregado a la pulsión de muerte de sí mismo y de toda otra forma de vida y civilización, como observamos en La carretera de Cormac McCarthy e, incluso, en la trilogía Maddaddam de Margaret Atwood. También hay ficciones posapocalípticas en las que se nos presenta la sociedad varios años después del cataclismo con un contrato social opresivo y absurdo como en The Chrysalids de John Wyndham o The Long Tomorrow de Leigh Brackett.

A pesar de que el escenario descrito arriba ocupa un lugar definitorio en el imaginario actual sobre la ficción posapocalíptica, no todas estas obras nos ofrecen una sociedad surgiendo de entre las ruinas con un nuevo contrato social en mano; algunas reflexionan sobre el problema de continuar con un contrato social caduco más allá del "fin del mundo". En estos casos se proyecta hacia el futuro aquello mismo que esta ficción se complace en eliminar de raíz con el fin de analizar el estado de la moral humana. Esto es lo que sucede, me parece, en la mayoría de los textos mexicanos que podríamos incluir dentro de esta categoría de "posapocalipsis".

En la literatura mexicana existen pocas obras de ficción que podrían llamarse propiamente posapocalípticas, siendo bastante raras aquellas del tipo que han ido definiendo el género cual se ha descrito arriba: textos en los que la humanidad se ve obligada a vivir después del cataclismo final, reconstruir la sociedad mediante un nuevo contrato social en una feroz lucha contra quienes sí han logrado organizarse pero para robar, matar y sobrevivir, por mera voluntad de vida, mediante la bestialidad y la violencia. Una novela mexicana reciente (2012), que curiosamente retoma este patrón, Todo era oscuro bajo el cielo iluminado de Carlos Augusto González Muñiz, nos presenta la vida en la Cd. de México sin electricidad y con los problemas descritos arriba en relación con la organización de la sociedad en un nuevo orden. Muy revelador resultaría una comparación de la representación del contrato social posapocalíptico de esta novela 
mexicana con aquello que se narra en obras como CyberStorm (2013) de Matthew Mather, pues en ambos casos se presentan escenarios y personajes similares con resultados muy distintos.

A pesar de que los novelistas mexicanos muestran poca inclinación hacia la representación de ficciones de este tipo, de muchas maneras parte de nuestra tradición literaria es sumamente posapocalíptica; sobre todo puede percibirse esta sensibilidad en aquellas obras en las que se comunica una actitud trágica ante la historia y una desesperanza sobre el futuro del país, tópicos recurrentes en la ficción mexicana por lo menos desde Los de abajo (1915) de Mariano Azuela. De modo que, vista así la historia de la literatura, puede decirse que no solo hay una sensibilidad, sino hasta una veta importante de obras que permiten proponer la categoría de "ficción posapocalíptica mexicana" como una variante de la ficción posapocalíptica. Pienso en obras como El resplandor (1937), de Mauricio Magdaleno; Los peregrinos inmóviles (1944), de Gregorio López y Fuentes; Pedro Páramo (1955), de Juan Rulfo; Cristóbal Nonato (1987), de Carlos fuentes, etc. El desplazamiento de la identidad mexicana hacia lo indígena que se registró en el imaginario nacional durante el siglo XIX y, más particularmente, en la primera mitad del siglo XX no solo permite repensar la Conquista como el apocalipsis mexicano, sino que lleva a interpretar nuestra historia posterior como posapocalíptica. De ahí que los productos culturales como la literatura, sobre todo aquellos que tratan las problemáticas nacionales, puedan ser interpretados naturalmente como textos de este orden, como de hecho ha sucedido en la obra de los autores presentados arriba y de autores contemporáneos como Mario González Suárez, Yuri Herrera y Juan Villoro, entre otros.

Desde esta postura reflexiono aquí sobre el sentido contemporáneo del contrato social en el México ficcional del siglo XXI a partir de dos novelas recientes de Homero Aridjis: Los perros del fin del mundo (2012) y Ciudad de zombis (2014). Obras muy similares entre sí, pues en ambas la trama narrativa de la búsqueda de un ser querido se nos presenta a la luz de una organización social absurda que coloca al hombre en "estado natural" gozando de los beneficios que ofrece estar sometido a un convenio social. Si bien estas 
novelas no representan escenarios explícitamente posapocalípticos (como tampoco lo hacen las novelas citadas arriba), la situación de vida política e individual imaginada en estas obras no es posible sino desde una lectura que perciba las cosas como más allá de los límites del fin.

Estas obras permiten leerse de muchas otras maneras, pero la postura apocalíptica en la obra de Homero Aridjis es evidente en sus textos literarios o en sus declaraciones en torno a la catástrofe ambiental ("ecología") y ha sido motivo de investigación sobre su obra en artículos como los de Lucía Guerra, "El último Adán: visión apocalíptica de la ciudad en la narrativa de Homero Aridjis"; Javier Ordiz, "Historia, apocalipsis y distopía en la narrativa de Homero Aridjis" y Laurence Pagacz, "Apocalipsis barroco en Gran teatro del fin del mundo de Homero Aridjis", etc. De modo que una lectura apocalíptica de su obra, me parece, queda suficientemente justificada.

Sin embargo la lectura posapocalíptica que realizo en este trabajo, más allá del apocalipsismo de Aridjis y de las reflexiones filosóficas actuales sobre el sentido de la vida después del "fin de los tiempos", también se valida por la presencia de estrategias narrativas propias de la literatura de este tipo que encontramos en ambas novelas aquí analizadas. Por una parte señalo la presencia de zombis en el sentido posapocalíptico ${ }^{1}$ que surgen de repente en Ciudad de Zombis, pues su aparición se representa como un evento al modo de los eventos que marcan el fin del mundo en este género de ficción: "El primero que vio a los zombis fue Roberto Rodríguez" (19). Por otra, la recuperación de la cosmología apocalíptica mesoamericana que se observa en Los perros del fin del mundo, sobre la que el autor ha dicho que: "Los perros salen del inframundo y empiezan a estar en las calles porque mi visión en esta novela, por los horrores que estamos viviendo, es que casi no hay diferencia: el supramundo

${ }^{1}$ Es decir, el estilo del muerto viviente popularizado por George Romero en su Night of the Living Dead (1968), a diferencia del zombi tradicional del folclor antillano (ver la introducción a Bishop, Kyle William. American Zombie Gotbic). 
parece también nuestro inframundo, vivimos una especie de infierno" (Bucio); al plantearse la realidad como un mundo muerto se está presentando la vida en un post-apocalipsis.

En este escrito parto de las premisas del libro de Claire P. Curtis, Postapocaliptic Fiction and the Social Contract. Curtis considera que hay tres tipos de ficción posapocalíptica: premoderna, moderna y posmoderna, y que de estas es la moderna la que reflexiona sobre el proceso de comenzar de nuevo a construir la sociedad (2), también afirma que el espacio para la exploración de las cuestiones relacionadas con el "estado natural" y el "contrato social" es la ficción posapocalíptica del siglo XXI (4-5). Por razones que serán obvias, mi trabajo se desvía del de Curtis en varios sentidos: primero, al incorporar al estudio de este tipo de ficción textos de la tradición hispana; segundo, al abordar desde ese enfoque obras que no son explícitamente posapocalípticas y, finalmente, al considerar qué sucede cuando después del fin el contrato social excede los límites de su existencia. Este trabajo surge de no haber encontrado entre las distintas formulaciones de Curtis una que dé cuenta del problema de la representación del desplazamiento del contrato social en este género de ficción como sucede en la literatura mexicana.

Thomas Hobbes, en su Leviatán, alega que el hombre en estado natural, es decir, viviendo según las leyes de la naturaleza, se encuentra en guerra perpetua (151); que la vida en esa situación es solitaria, pobre, brutal y breve (84). En consecuencia, algunos teóricos del contrato social clásico, ${ }^{2}$ incluyendo a John Locke y al mismo Hobbes, suponen que los hombres no permanecen en ese estado natural sino que, gracias a un hipotético acuerdo social, desarrollan instituciones políticas, civiles, sociales, así como arreglos sobre la propiedad, etc. (Waldron 52), que permitan mejorar las condiciones de vida (Martin 246). De lo anterior se desprende una progresión, que no es ajena al pensamiento de la mayoría de estos

${ }^{2}$ Especialistas sobre el tema como David Boucher y Paul Kelly hacen la distinción entre teóricos del contrato social "clásico": Hobbes, Locke, Rousseau y Kant y los "modernos": Hegel, Marx, Gauthier, etc. 
teóricos, en la que el "hombre natural" pasa a formar parte de una organización social que le requiere contribuir al bien común (Forsyth 43). Por supuesto que Locke y Hobbes, ambos, entendían que el hombre no se despoja automáticamente de sus instintos naturales por el simple hecho de organizarse en sociedad, sino que reconocen que el individuo es obligado a reprimir esos instintos (por decirlo en términos modernos) a favor de los beneficios que la sociedad aporta (Forsyth 47; Boucher 13). De modo que, a pesar de no dejar de ser "hombres naturales" por entrar en el convenio del contrato social, sí se entiende de lo anterior que ambos estados no pueden actuarse en un mismo plano de existencia por ser mutuamente excluyentes. ${ }^{3}$

Puesto que la ficción posapocalíptica nos invita a reflexionar sobre la teoría del contrato social (Curtis 2) al presentarnos escenarios en los que se pone en juego la idea misma de contrato, el sentido del estado actual de ese constructo hipotético, la forma que adoptaría la reorganización de la sociedad luego de una catástrofe o la imposibilidad de limitar los impulsos animales del hombre, etc., me parece pertinente incorporar estos conceptos al estudio de las obras de la literatura mexicana contemporánea que considero se benefician de dichas reflexiones, dado lo que las formas o características particulares de esas narrativas nos dicen sobre la realidad o sobre nuestra manera de interpretar la realidad presente.

Tanto Los perros del fin del mundo como Ciudad de zombis proyectan una imagen sumamente pesimista de México. Los problemas que padecemos en el país, como el narcotráfico, la trata de personas, la extorsión, el secuestro, la corrupción política, la pérdida de valores cívicos y morales asociados con la decadencia de la familia como institución y la pobreza educativa, así como la violencia de género

${ }^{3}$ No conviene discutir aquí las combinaciones posibles en las que un individuo puede aceptar el contrato social al tiempo que sus acciones lo llevan a actuar como "hombre natural" (v. gr psicópatas), puesto que lo que nos interesa es la sociedad en su totalidad conformada por individuos, cada uno manteniendo un balance entre las demandas sociales y sus propios instintos antisociales. 
$\mathrm{y}$, en general, todo tipo de criminalidad y vandalismo concebible, son llevados en estas novelas hasta el punto retórico de la adynaton (el exceso), mediante los recursos de la acumulación y la repetición. De esta manera, lo que parecería ser un defecto narrativo cobra sentido especial, pues de otra forma ambas novelas no son sino una reiterante letanía (valga el énfasis) de los males sociales y políticos que nos aquejan. El exceso en el que el texto se desarrolla ayuda a presentar una imagen de México como un sitio que no podría ser más distópico, ni siquiera si se representara como un mundo explícitamente posapocalíptico, pues es imaginado justamente en términos que se apegan a las descripciones comunes del "estado natural" hobbesiano recurrentes en este tipo de ficción, como lo afirma Curtis (43): un mundo de "todos contra todos" y en donde la vida humana, más allá de los placeres inmediatos y breves que se puedan obtener, es terriblemente desesperanzada.

Sucede, sin embargo, que a pesar del inhóspito escenario con el que estas novelas representan al país, la nación mexicana continúa su vida moderna tal cual la conocemos: las instituciones propias del contrato social siguen visibles a modo de ciclorama para todos los sucesos que se nos ofrecen al irse desarrollando las acciones. Por ejemplo, México no solo cuenta con un gobierno democrático y republicano (Ciudad 81; Perros 48), sino que además los ciudadanos gozan de servicios de comunicación y transporte (Ciudad 32; Perros 73), de infraestructura urbana (Ciudad 15), de seguridad social, de seguridad pública (Ciudad 14; Perros 70), etc.; servicios que en su existencia misma contradicen la condición de "estado natural" que se pensaría indispensable para reconocer estas novelas como textos posapocalípticos. Dicha contradicción, entonces, se nos presenta como una aporía en tanto que, lógicamente, no puede concebirse una realidad en la que exista un contrato social sin que al mismo tiempo existan contratantes.

Lo anterior resulta problemático porque en ambas novelas el orden esperado del contrato social y el caos resultante de la vida del hombre en "estado natural", contrarios como son, ocupan el mismo espacio. Esto sucede al proyectar, y más que eso, desplazar hacia el posapocalipsis el convenio actual, con todo lo que ello 
implica. Esta aporía, como es de esperarse, produce en la novela escenas absurdas e imposibles, pues se nos da de facto una organización social, pero los partícipes de esta sociedad viven y actúan más allá de los límites que permitirían mantener esa comunidad imaginada en pie. Metafóricamente podría antojarse imaginar el México de estas novelas como un objeto estático en el aire sin una sola columna de soporte. Una cita tomada de Los perros del fin del mundo nos permitirá captar esta paradoja:

Varios emos estaban reunidos debajo de la estructura metálica de la línea 2 del Metrobuis... Alli vienen los punketos-un emo descubrió a los miembros de una tribu rival que invadía su territorio... Los emos se lanzaron al ataque. Los punketos huyeron ... En ese momento un comando de policias con chalecos antibalas y tatuajes en los brazos empezó a disparar... bloquearon las salidas para que los emos y los punketos no pudieran escapar... dispararon a diestra y siniestra, alcanzando a algunas personas que pasaban por la plaza ... se fueron los policias, pero llegaron los granaderos con garrotes y escudos para tundir a los caídos ... no eran policías, eran sicarios disfrazados. Se equivocaron, vinieron por los miembros de una banda rival . . en eso irrumpieron los Hare Krishnas con cantos y bailes (69-71).

En la cita anterior, verdaderamente sinecdótica de los sucesos de ambas novelas, observamos una sociedad civil organizada, pues se supondría que alguien tiene que administrar estos recursos y dirigir estas instituciones. Sin embargo, tanto policías como civiles se comportan de manera que hace imposible imaginar que dicha sociedad se mantenga en pie. La novela no hace pausas para reflexionar, como podría hacerlas el lector en un afán de cuestionar la verosimilitud del relato, quién opera el metrobús o quién construye las estructuras metálicas y las plazas si todo mundo se encuentra en guerra perpetua: asesinando, robando, secuestrando, etc.

Curiosamente, esta aporía que observo en ambas novelas de Aridjis, y que podría ser entendida como una percepción idiosincrática del autor sobre la condición actual de la vida en México ha sido registrada ya por otros observadores contemporáneos de 
nuestra realidad, no solo novelistas. ${ }^{4}$ Carlos Monsiváis, por ejemplo, escribía en Los rituales del caos: "México, ciudad post-apocalíptica. Lo peor ya ocurrió ... y sin embargo la ciudad funciona de modo que a la mayoría le parece inexplicable" (21). En este pasaje se hace referencia al problema específico de la sobrepoblación del DF, pero quisiera subrayar que lo que está de fondo es el extrañamiento que resulta de advertir los excesos, es decir, sobre una situación de vida que desafía la lógica al superar los límites de lo posible.

Esta aporía social que nos presentan las novelas de Aridjis, al igual que la ciudad de México de Carlos Monsiváis, se resuelve al considerar el concepto del posapocalipsis como el espacio de los excedentes, en tanto que este tipo de ficción se entiende como aquella que trata sobre lo que sucede después del fin del mundo. Como explica James Berger:

The apocalypse, then, is The End, or resembles the end, or explains the

end. But nearly every apocalyptic text presents the same paradox. The end is never the end. The apocalyptic text announces and describes the end of the world, but then the text does not end, nor does the world represented in the text, and neither does the world itself. In nearly every apocalyptic presentation, something remains after the end (27-28). ${ }^{5}$

${ }^{4}$ Lo mismo puede decirse de otras realidades hispanoamericanas. Amanda Salvioni nos dice que se puede ver la narrativa apocalíptica latinoamericana como manifestación de una crítica social que apunta al fracaso del modelo de desarrollo capitalista e industrial, implementado con empeño por las sociedades americanas, y radicalizado por las políticas neoliberales de los años 90. Casos emblemáticos serían los cambios sociales experimentados en México después de la firma del NAFTA, y las transformaciones producidas en Argentina durante y después de la década del neoliberismo menemista. En ambos países, las narraciones han cobrado un tinte más bien postapocalíptico, pues pretenden ser testimonios de una catástrofe ya ocurrida (305).

5 " $\mathrm{El}$ apocalipsis, entonces, es El fin, o se parece al fin o explica el fin. Pero casi cada texto apocalíptico presenta la misma paradoja: el fin nunca es El fin. El texto apocalíptico anuncia y describe el fin del mundo, pero el texto no termina 
Aquello que permanece después del fin es un excedente, pues nada debe permanecer después del fin. Pero ello ha superado los límites y la ficción posapocalíptica es precisamente aquella que trata sobre lo que sucede en ese tiempo-espacio del más allá, particularmente de excedente de vida humana como individuos, hombres y mujeres naturales. Por tal razón la exploración sobre el valor del contrato social requiere que se plantee la creación de uno nuevo mientras que la permanencia de un contrato social que pueda continuar funcionando más allá del fin es problemática, pues cancela la posibilidad de una ficción posapocalíptica.

Sobre la posibilidad y el sentido de la vida más allá de los límites James Berger, en su libro sobre el posapocalipsis, recurre al concepto lacaniano de la segunda muerte (Écrits 262) que Žižek desarrolla en El sublime objeto de la ideología. Žižek toma la distinción que hace Lacan (260) entre: "la muerte natural, que es parte del ciclo natural de generación y corrupción, de la transformación continua de la naturaleza, y la muerte absoluta -la destrucción [o] la erradicación del ciclo, que entonces libera a la naturaleza de sus propias leyes y abre el camino a la creación de nuevas formas de vida ex nihilo" (Žižek 180). Es decir, una muerte simbólica que puede ocurrir mucho antes de la otra, la final, que es la biológica. El espacio entre estas dos muertes es el espacio del posapocalipsis de la ficción contemporánea.

La posibilidad de la existencia de este espacio posapocalíptico nos lleva a reflexionar sobre las manifestaciones artísticas que imaginan la vida después del fin simbólico y antes del biológico o total. Žižek, que presenta dicho concepto para discusión estética, no se dedica a examinar el texto posapocalíptico en sí, pero señala que en el imaginario este lugar es un espacio habitado por "monstruos aterradores" (181). Curiosamente observamos en este género de ficción una insistencia o necesidad de poblar el fin del mundo (un

con el fin, tampoco termina el mundo representado en el texto, así como tampoco termina el mundo mismo. En casi cada representación apocalíptica, algo queda después del fin" (mi trad.). 
desplazamiento temporal por el espacial de los confines del mundo medieval, también habitado por seres monstruosos) de zombis, caníbales y otras criaturas similares contra quienes deberán luchar aquellos que buscan reconstruir el mundo.

Como es de esperarse en este tipo de ficción, en la nación posapocalíptica de Aridjis, los habitantes son seres monstruosos. Siguiendo la nomenclatura de Ciudad de zombis para ambas obras, los actantes son "muertos en vida", "zombis" o "vivos muertos". Incluso los personajes principales y los narradores desde cuyo punto de vista observamos el mundo, y que se encuentran de alguna manera luchando contra dichos seres, no dejan de parecer también ellos mismos seres decadentes. El narrador en Ciudad de zombis, por ejemplo, se define a sí mismo como un "pre-muerto viviente" (95) en su desesperanzada obsesión por encontrar a sus seres queridos en este mundo posapocalíptico. Además, saben bien que toda búsqueda solo podrá devolverles monstruos, pues como se observa en Ciudad de rombis una vez que Daniel (narrador) ha encontrado a su hija Elvira y la lleva de vuelta a casa: "Le quité el sarape y comprobé que no era Elvira. Tenía las facciones hendidas y los ojos apagados. Había en ella fealdad y furia. Era la niña del tipo que ve cosas. Una criatura extraña, mayor que Elvira, algo marchita y tan vieja que parecía sin edad" (330). El final esperado no podía ser diferente dado el pesimismo de la obra. Conjeturo que tampoco espera el lector encontrar al final que todo ha sido una pesadilla, pues el narrador ha dejado claro desde un inicio que se trata de una realidad pesadillesca (Perros 152; Ciudad 85) de la que no se puede escapar.

Los personajes de ambas novelas habitan un mundo cuyo contrato social, al ser trasladado hacia el posapocalipsis, no puede ser más que una ley muerta en tanto que ha dejado de tener significado. Ninguno de los personajes, ni Daniel Medina o Roberto, en Ciudad de Zombis, ni José Navaja en Los perros del fin del mundo, pueden apelar a un poder superior, humano o divino, capaz de ayudarles a resolver sus casos. El sacerdote Douglas Martínez predica: "No estoy aquí para hablar de la escatología apocalíptica ni para instruir sobre el reino milenario. No puedo explicar lo que pasa en las calles, pero algo terrible está pasando" (150); mostrando que la religión no tiene en 
este caso capacidad para tratar aquellos temas que le corresponden. Y en cuanto a la "multitud huérfana" se nos dice que: "No el presidente no el gobernador no el obispo no el banquero eran los importantes, sino los cadáveres de gente de poca monta . . El concepto de poder había desaparecido y en la procesión el pueblo menudo llevaba retratos de celebridades del cine, la canción o el deporte" (320).

Observamos pues que, aunque las autoridades y las instituciones están ahí, incluyendo la religión y otras formas de organización social, estas no cumplen las funciones para las que han sido creadas y, como tal, solo son el cascarón vacío de un mundo que si bien ha dejado de ser no ha dejado de existir: conserva aún, como se ve, un resto de vida, aunque se encuentre inevitablemente señalada para la aniquilación total. Podría argumentarse que en la búsqueda de un otro poder como "celebridades", estamos ante la re-elaboración del contrato social, solo que uno distinto al que se nos ha presentado en Occidente. En ese sentido podría alegarse que la ficción posapocalíptica, en tanto que nos presenta el renacer de una nueva sociedad mediante el contrato social y el enfrentamiento entre individuos -unos que buscan destruir toda esperanza y otros que desean mantener vivas ciertas instituciones sociales-, es una vuelta a la dicotomía civilización y barbarie explorada en la literatura hispanoamericana del siglo XIX, pues de igual manera se observa en esta ficción la necesidad de representar un modelo para la construcción de un mundo luego de un evento, como el de la Independencia que marca un límite y un nuevo comienzo.

Pero la ficción posapocalíptica mexicana va más allá de la dicotomía civilización y barbarie. En el caso de las novelas de Aridjis, el México absurdo y contradictorio que imagina no representa estos dos estadios clásicos del imaginario sobre la nación, pues no nos ofrece a la civilización en pugna con la barbarie, que sería el modelo tradicional de concebir un país en proceso de firmar un contrato social; más bien observamos el otro extremo: el de su decadencia final, que no es otra cosa que la representación de la vida una vez que se ha destruido la continuidad del ciclo de esa existencia.

Esta imagen del posapocalipsis como un plus ultra, como lo que queda de vida después del fin, puede observarse a lo largo de ambas 
novelas. En Ciudad de Zombis México ha sido invadido por los Estados Unidos a la vez que el gran señor del crimen de Misteca, el señor de los zombis, ha sucumbido (presuntamente) ante las "fuerzas del orden”. En ese momento se representa un movimiento, quizá un despertar ciudadano a causa de una inconformidad. Al momento nada se sabe. Nos dice el narrador:

creí que eran estudiantes que se oponían a la invasión norteamericana, pero no, eran meseras, teiboleras, colegialas, empleadas de comercios y oficinas, amas de casa, reinas de belleza, y hasta niñas, con playeras, pantaloncillos, gorras y zapatos blancos protestando por la muerte del Señor de los Zombis . . . Acompañadas de música de banda y de tambora, y de pancartas. Un zombi vivo muerto mostraba un letrero: Misteka no te ekivokes aun muerto soy tu dueño: Carlos Bokor. Una chica con sudadera roja agitaba una cartulina: Bokor, te amo, hazme un bebé. Portaba un cartel un niño enmascarado: Bokor, yo kiero ser sikario. Dos mujeres topless expresaban: Bokor es un asesino, pero es nuestro asesino. Una pancarta decía: Vivan nuestros narkos y tiranosaurios que mantienen prósperos nuestros picaderos y burdeles, amamos sus jeringas y sus armas largas, sus coches y sus putas último modelo (325-26).

Los oficios de algunos de estos manifestantes remiten a actividades propias de una sociedad civil organizada en torno a un contrato social: meseras, colegialas, empleados de ventas, que requieren a su vez, restaurantes, escuelas y comercio, pero también es evidente por lo que se exige en las pancartas que este grupo heterogéneo se manifiesta -actividad, sea dicho de paso, solo posible dentro de un contrato social que permita la libertad de expresión- para declararse a favor de un estado anti-social, o "estado natural". Observamos en la cita anterior que lo que parecer ser un despertar ciudadano no es tal, sino una reacción encaminada a extender la vida cual es hasta que esta se termine. 
La ficción posapocalíptica de Aridjis no es, por tanto, nada optimista: carece de fe en el futuro y no propone al final una reorganización social o un despertar popular para cambiar el rumbo que lleva la sociedad; ni siquiera intenta señalar los males del país con la esperanza de que los ciudadanos hagan conciencia de ellos y estos se corrijan. Es por esta razón que propongo que la representación de la realidad que se ofrece en estas dos novelas es aporística y no satírica (aunque ambas no sean mutuamente excluyentes), pues no leemos un "ataque a los vicios de la sociedad". En su estudio sobre la sátira, Rubén Quintero afirma que la sátira requiere que " $\mathrm{X}$ " no sea hipotéticamente incorregible, sino que depende de la creencia en un cambio (2). Tampoco se observa que Aridjis intente cancelar (y ocultar) la seriedad de ese ataque mediante la representación carnavalesca a través de la risa, que, como señala Luis Beltrán, debe ser considerada uno de los componentes de la sátira (257-58), sino que en estas novelas se narra la confusión de la realidad mexicana mejor entendida a la luz de la ficción posapocalíptica.

Los perros del fin del mundo y Ciudad de Zombis ofrecen una mirada cínica y fatalista del mundo que concuerda con la actitud posapocalíptica de la sociedad contemporánea que se siente viviendo irremediablemente más allá del fin de los tiempos, más allá de la posibilidad de revertir la muerte que amenaza al mundo. Este sentir no solo se manifiesta en la ficción que aborda estos temas, sino que ha tenido también amplia resonancia en discusiones filosóficas sobre el sentir de nuestros tiempos en pensadores como Jean Baudrillard, Jean-Luc Nancy, Slavoj Žižek, ${ }^{6}$ etc.

La visión sobre el fin del mundo, y más allá, de estas novelas y de otras obras mexicanas similares, parece surgir de preocupaciones que son distintas a las de los textos occidentales de este género, pues en su desarrollo contemporáneo este suele albergar funciones

"Jean Baudrillard en The Illusion of the End (10); "The Anorexic Ruins" en Kamper, Dietmar y Cristoph Wulf. Looking Back on the End of the World. Semiotext(e) 1989. Nancy, Jean-Luc. The Sense of the World (5). Slavoj Žižek, El sublime objeto de la ideología (260). 
didácticas que invitan al lector a reflexionar sobre los valores del mundo que habita y a preocuparse por las consecuencias de aquellos comportamientos que pueden dar lugar a un apocalipsis. La preocupación ha sido señalada por Žižek, quien ha designado los problemas más serios que enfrenta la humanidad con el título de los "cuatro jinetes del apocalipsis contemporáneo": a saber, "la crisis ecológica, las consecuencias de la revolución biogenética, los desequilibrios dentro del propio sistema ... y el explosivo crecimiento de las divisiones y exclusiones sociales" (Viviendo 8). Son estos mismos "jinetes" los que aparecen como las causas del apocalipsis en la ficción contemporánea y que ha tenido importante recepción en valiosas novelas del género como en las obras de J.G. Ballard y Margaret Atwood, por no decir nada de los cientos de films del género que han aparecido a lo largo de las décadas.

En la ficción mexicana posapocalíptica no suele haber una preocupación por dar cuenta de las consecuencias a futuro de los desequilibrios económicos ni de los excesos de la ciencia, sino un retrato, si bien estilizado y ficcionalizado, de la realidad actual, las consecuencias de la acción de los mismos “jinetes" que apenas comienzan a amenazar a las sociedades modernas: desequilibrios del sistema, injusticia y exclusión social. Quizá, y esto es lo que me parece más importante, es justo el punto temporal desde donde se narra el posapocalipsis en donde radica la diferencia entre la ficción mexicana y otras formas de esta literatura. James Berger explica que en la ficción posapocalíptica

Temporal sequence becomes confused. Apocalyptic writing takes us after the end, shows the signs prefiguring the end, the moment of obliteration, and the aftermath. The writer and reader must be both places at once, imagining the postapocalyptic world and then paradoxically "remembering" the world as it was, as it is (28). ${ }^{7}$

7 "La secuencia temporal se nos hace confusa. La escritura apocalíptica nos proyecta más allá del fin, nos muestra los signos que prefiguran el final, el mo- 
La ficción posapocalíptica se narra en pasado desde un futuro con respecto al momento de lectura. Las obras de Aridjis, en cambio, narran el posapocalipsis desde el presente mismo. Es decir, narra las condiciones de vida existentes del presente como las condiciones de un mundo verdaderamente posapocalíptico.

De idéntica manera que con el apocalipsis de la filosofía occidental posmoderna, el apocalipsis de la ficción mexicana ya sucedió. Para imaginar la posibilidad de la catástrofe no hemos tenido que depender de los terribles sucesos del siglo XX, ni proyectarnos hacia una realidad futura inminente. Más bien lo inventamos mucho antes: lo creamos justo en el momento en el que decidimos que era conveniente tener a la mano en nuestro imaginario un evento capaz de justificar el fracaso recurrente del contrato social, como lo hace Aridjis. Desde esta interpretación de nuestra realidad, la ficción mexicana nos convierte en seres posapocalípticos, muertos vivientes que no podemos sino seguir con nuestro excedente de vida en un "estado natural" sobre un contrato social sin vigencia, pues de nada sirve reorganizarse socialmente si solo se espera el exterminio final y absoluto.

\section{Bibliografía}

Aridjis, Homero. Ciudad de zombis. Alfagura, 2014.

_. "La era de la ecología; El sol de la tierra". Biblioteca Virtual Miguel de Cervantes, 2014, http://www.cervantesvirtual.com/ nd/ark:/59851/bmc156c8.

—. Los perros del fin del mundo. Alfaguara, 2012.

Baudrillard, Jean. The Illusion of the End. Traducción de Chris Turner. Stanford U.P., 1994.

mento de la obliteración total, así como lo que le sigue. El escritor y el lector, por tanto, deben encontrarse en ambos sitios al mismo tiempo, deben imaginar lo posapocalíptico y al mismo tiempo, paradójicamente, deben recordar el mundo como fue, es decir, como es" (mi trad.). 
Beltrán Almería, Luis. La imaginación literaria. La seriedady la risa en la literatura occidental. Montesinos, 2002.

Berger, James. After the End: Representations of Post-Apocalypse. U. of Minnesota P., 1999.

Bishop, Kyle William. American Zombie Gothic. The Rise and Fall (and Rise) of the Walking Dead in Popular Culture. Ed. Kindle, McFarland and Co., 2010.

Boucher, David y Paul Keller. "The Social Contract and its Critics. An Overview". The Social Contract from Hobbes to Rawls. Boucher y Keller, Routledge, pp. 1-34.

Boucher, David y Paul Keller, editores. The Social Contract from Hobbes to Rawls. Routledge, 1994.

Bucio, Erika P. "Narra el apocalipsis". Reforma [Cd. de México], 13 Junio 2012, p. 27.

Curtis, Claire P. Postapocalyptic Fiction and the Social Contract: We'll Not Go Home Again. Ed. Kindle, Lexington Books, 2010.

Forsyth, Murray. "Hobbes Contractarianism: A Comparative Analysis". Boucher y Keller, pp. 35-50.

Guerra, Lucía. "El último Adán: visión apocalíptica de la ciudad en la narrativa de Homero Aridjis". Contexto vol. 6, no. 8, 2002, pp. 81-103.

Hobbes, Thomas. Leviathan: Or, the Matter, Forme \& Power of a Commonwealth, Ecclesiasticall and Civill. Editado por A. R. Waller, Cambridge UP, 1904.

Lacan, Jacques. Écrits. Traducción de Bruce Fink, Norton and Co., 2006.

Martin, Rex. "Economic Justice. Contractarianism and Rawls's difference principle". Boucher y Keller, pp. 245-66.

Monsiváis, Carlos. Los rituales del caos. Ediciones Era, 1995.

Nancy, Jean-Luc. The Sense of the World. Traducción de Jeffrey S. Librett. U of Minnesota P, 1997.

Ordiz, Javier. "Historia, apocalipsis y distopía en la narrativa de Homero Aridjis", Hipertexto no. 12, 2010, pp. 3-14.

Pagacz, Laurence. "Apocalipsis barroco en Gran teatro del fin del mundo de Homero Aridjis", Hipogrifo vol. 2, no. 2, 2014, pp. 81-94. 
Quintero, Ruben. A Companion to Satire: Ancient and Modern. Wiley-Blackwell, 2011.

Salvioni, Amanda. "Lo peor ya ocurrió. Categorías del postapocalipsis hispanoamericano: Alejandro Morales y Marcelo Cohen". Altre Modernità. Rivista di studi letterari e culturali. Extra 1, 2013, pp. 304-16.

Waldron, Jeremy. "Social Contract Versus Political Anthropology". Boucher y Keller, pp. 51-72.

Žižek, Slavoj. El sublime objeto de la ideología. Traducción de Isabel Vericat Nuñez, Siglo XXI, 2003.

- Viviendo en el final de los tiempos. Traducción de José María Amoroto Salido. Akal, 2012. 